\title{
Lifestyle and Nutritional Status of School Going Adolescent Girls in a Semi Urbon Area of West Bengal, India
}

\author{
*Purushottam Pramanik, Subha Bose Banerjee, Antara Ghosh \\ Post Graduate Department of Physiology, Hooghly Mohsin College, Chinsurah, Hooghly, West Bengal, India
}

\begin{abstract}
Adolescence is a journey from the world of childhood to the world of adulthood. In India adolescents constitute $21.4 \%$ of the population that comprises one-fifth of the total population. The health and nutritional status of the children is an index of the national investment in the development of future manpower. Thus present study was undertaken to assess the nutritional status of school going adolescent girls in semi urban area of West Bengal. This study was conducted among 746 school children of 11-18 years studying in four girls' schools in Hooghly district. School was selected by simple random sample in two municipality areas. Nutritional status was evaluated using anthropometric indicators recommended by WHO(World Health Organization) experts committee. Height for age below $3^{\text {rd }}$ percentile of NCHS (National Centre for Health statistics) /WHO reference values was classified as stunting. Thinness was defined as BMI-for-age $<5^{\text {th }}$ percentile of WHO/NCHS standard data. Over weight and obese were defined as BMI-for-age $>85^{\text {th }}$ percentile and $>95^{\text {th }}$ percentile respectively. The present study highlight the duel burdens of underweight and overweight in semi urban adolescent girls. Overweight is more urgent problem than underweight. Lifestyle (physical activity and fast food intake habit) was one of the contributing factor of overweight. To minimized both forms of malnutrition, it is essential to educate and create awareness programmes at the community levels. Health education programmes and effective policies are urgently required to promote healthy eating and physical activity.
\end{abstract}

Keywords: Adolescent girl, nutritional status, fast food, physical activity

\section{Introduction}

Adolescence is a journey from the world of childhood to the world of adulthood. This period is very crucial since these are the formative years in the life of an individual when major physical, psychological and behavioral changes take place. Adolescence is a vulnerable period in human life cycle when nutritional requirements increase due to adolescent growth spurt. This period is characterized by rapid increase in height and weight and hormonal changes resulting in sexual maturation (1). Adolescence, one of the nutritional stress periods of life with profound growth, comes with increased demand for energy, protein, minerals and vitamins (2). Malnutrition, both under nutrition and over nutrition resulting from imbalance of nutrients is of public health significance among adolescents across the world (3). The coexistence of overweight/obesity and under weight is rather common in developing countries and is found to be increased proportionally over time $(4,5)$. In India adolescents constitute $21.4 \%$ of the population (6) that comprises one-fifth of the total population. The health and nutritional status of the children is an index of the national investment in the development of future manpower. Several studies have investigated the nutritional status of children and adolescents from different parts of India $(7,8)$.In India alone, there are approximately 60 million children who are under weight $(9)$, and this prevalence is higher in rural areas compared to urban areas (10). However, India is now also beginning to experience the emerging problem of overweight (11). A recent study along Indian children in the age group of 6-18 years suggests the existence of double burden of underweight and over weight (12). Most of the studies regarding nutritional status of adolescent girls were carried out in rural areas and urban areas. No or little research on nutritional status of adolescent girls yet was undertaken in semi urban areas. Thus present study was undertaken to assess the nutritional status of school going adolescent girls in semi urban area of West Bengal.

\section{Material And Methods}

Study subject: The present study was conducted among school children of 11-18 years studying in four girls' schools in Hooghly district during their school hours from March 2013 to April 2014. The prior written permission of school authority was taken. Written consent from the parents of the students experimented in the study was obtained. The ethical clearance was duly sought from the Departmental Ethical Committee, Department of Physiology, Hooghly Mohsin College since the method was noninvasive. The subjects of this study were chosen at random irrespective of socioeconomic status and religion so that reflection of an overall picture of menstrual health status of study region could be achieved. All students who were willing to participate in the study were included in the study. They were invited to answer the questionnaires, which dealt with 
background information such as age, physical activity and dietary habit. We excluded the students who are suffering from any chronic health condition and are using any medicines for long duration.

Measurement of body weight: Body weight was measured using bathroom scale accurate to $0.5 \mathrm{~kg}$. The scale was kept on a flat surface and adjusted with ' 0 ' mark. Now the subject was requested to step on it in bare feet. Weights were taken in light cloth. Weight was recorded to the nearest $0.5 \mathrm{~kg}$.

Measurement of body height: Height was measured using anthropometric rod. Height of the subject was recorded without footwear and expressed to the nearest $0.1 \mathrm{~cm}$.

Estimation of body mass index (BMI): BMI was calculated from the height and weight using following equation: BMI $\left(\mathrm{kg} / \mathrm{m}^{2}\right)=$ weight $(\mathrm{kg}) /$ height $^{2}(\mathrm{~m})$. BMI-for-age $<5^{\text {th }}$ percentile of WHO/NCHS standard was considered as thin, BMI for age between $5^{\text {th }}$ to $85^{\text {th }}$ percentile considered as normal.

Study of dietary practices: dietary practices were assessed by putting questions on dietary preference, junk food intake and, frequency of intake of green vegetable.

Junk foods include chips, chocolate, icecream, soft drinks, burgers, pizzas, chowmein, pakora, samosa etc (13). Junk food consumption was studied on the basis of frequency of eating:

Category a: junk food intake $0-1$ day/ week

Category b: junk food intake 2-3 days/ week

Category c: junk food intake 4-5 days/ week

Category d: junk food intake regularly 6- 7 days/ week

Study of physical activity: Physical activity was ascertain by asking for daily physical activity (running, fast walking, cycling, dancing). Physical activity was divided into four categories by modifying the method of Soudarssanane et al (14): Very mild ( $<1$ hour/day); Mild (1hr/day); moderate (2-3hour/day) and heavy ( $>3$ hour/day).

Determination of nutritional status: Nutritional status was evaluated using anthropometric indicators recommended by WHO experts committee. Height for age below $3^{\text {rd }}$ percentile of NCHS/WHO reference values was classified as stunting (15). Thinness was evaluated using WHO recommended age-specific cut off point based on WHO reference data. Thinness was defined as BMI-for-age $<5^{\text {th }}$ percentile of WHO/NCHS standard data. Over weight and obese were defined as BMI-for -age $>85^{\text {th }}$ percentile and $>95^{\text {th }}$ percentile respectively (16).

Statistical analysis: the parameters taken were analyzed statistically to find out the mean and standard deviation. Percentile of height, weight and BMI were computed. These were compared with existing international standards for evaluation of nutritional status of the selected subjects. Correlation between obesity and frequency of fast food intake and physical activity was estimated. Chi square test was used to estimate the significance of correlation. $\mathrm{P}<0.05$ was consider as significant.

\section{Results}

Total 811 girls were interviewed but 65 girls were excluded. Age wise distribution subjects were given in table 1. All the subjects are unmarried. Age varies from 11 to 18 years with average of 14.67 years. $4.9 \%$ girls were coming from Hindu families, 31.36\% from Muslim and 3.69\% from other religions.

Table-1: Age wise distribution of study subjects

\begin{tabular}{|l|l|l|l|}
\hline Characteristics & \multicolumn{2}{|l|}{ Number } & Percentage \\
\hline \multirow{5}{*}{} & 11 & 28 & 3.75 \\
\cline { 2 - 4 } & 12 & 48 & 6.43 \\
\cline { 2 - 4 } & 13 & 133 & 17.83 \\
\cline { 2 - 4 } & 14 & 134 & 17.96 \\
\cline { 2 - 4 } & 15 & 164 & 21.98 \\
\cline { 2 - 4 } & 16 & 118 & 15.82 \\
\cline { 2 - 4 } & 17 & 71 & 9.52 \\
\cline { 2 - 4 } & 18 & 50 & 6.70 \\
\hline \multirow{5}{*}{} & Hindu & 624 & 83.65 \\
\cline { 2 - 4 } & Muslim & 122 & 16.35 \\
\cline { 2 - 4 } & Other & nil & ------ \\
\hline & Unmarried & 746 & 100 \\
\cline { 2 - 4 } & Married & Nil & ---- \\
\hline
\end{tabular}

The mean height, weight and BMI of the study subjects in different ages was given in table-2 
Table2: Mean of anthropometric parameters by age

\begin{tabular}{|l|l|l|l|}
\hline Age $($ year: month) & Height $(\mathrm{cm})$ & Weight $(\mathrm{kg})$ & $\mathrm{BMI}\left(\mathrm{kg} / \mathrm{m}^{2}\right)$ \\
\hline $11: 0$ to $11: 11(28)$ & $145.89 \pm 5.89$ & $36.89 \pm 9.52$ & $17.24 \pm 4.01$ \\
\hline $12: 0$ to $12: 11(48)$ & $147.7 \pm 5.84$ & $41.13 \pm 9.84$ & $18.73 \pm 3.72$ \\
\hline $13: 0$ to $13 ; 11(133)$ & $148.36 \pm 6.15$ & $41.95 \pm 8.72$ & $19.00 \pm 3.60$ \\
\hline $14 ; 0$ to $14: 11(134)$ & $151.37 \pm 4.90$ & $48.16 \pm 11.91$ & $20.88 \pm 4.39$ \\
\hline $15 ; 0$ to $15: 11(164)$ & $152.39 \pm 4.67$ & $46.79 \pm 10.42$ & $20.12 \pm 4.18$ \\
\hline $16: 0$ to $16: 11(118)$ & $153.00 \pm 6.98$ & $48.70 \pm 8.81$ & $20.77 \pm 3.33$ \\
\hline $17: 0$ to $17: 11(71)$ & $153.33 \pm 4.72$ & 49.298 .55 & $20.93 \pm 3.36$ \\
\hline $18: 0$ to $18 ; 11(50)$ & $152.60 \pm 6.63$ & $48.94 \pm 8.75$ & $20.94 \pm 3.00$ \\
\hline
\end{tabular}

Mean Height was far lower than median values of WHO standard. There was no significant difference of BMI of study subjects with median value of WHO standard.

Table-3: comparison of mean height and BMI of study subject with WHO standard

\begin{tabular}{|l|l|l|l|l|}
\hline & Median height $(\mathrm{cm})$ & Median BMI $\left(\mathrm{kg} / \mathrm{m}^{2}\right)$ & Present study \\
\cline { 2 - 5 } & WHO standard & Present study & WHO standard & 17.24 \\
\hline $11: 0$ to $11: 11(28)$ & 148.20 & 145.89 & 17.60 & 18.73 \\
\hline $12: 0$ to $12: 11(48)$ & 154.00 & 147.70 & 18.40 & 19.00 \\
\hline $13: 0$ to $13 ; 11(133)$ & 158.30 & 148.36 & 19.20 & 20.88 \\
\hline $14 ; 0$ to $14: 11(134)$ & 160.90 & 151.37 & 19.90 & 20.12 \\
\hline $15 ; 0$ to $15: 11(164)$ & 162.20 & 152.39 & 20.50 & 20.77 \\
\hline $16: 0$ to $16: 11(118)$ & 162.70 & 153.00 & 20.90 & 20.93 \\
\hline $17: 0$ to $17: 11(71)$ & 163.00 & 153.33 & 21.20 & 20.94 \\
\hline $18: 0$ to $18 ; 11(50)$ & 163.10 & 152.60 & 21.30 & \\
\hline
\end{tabular}

Prevalence of stunting of study subjects was represented in table-3. In respect to NCHS standard $31.37 \%$ of study subjects were stunted. Stunted was noted in all age group of study and maximum in 16 year age group subjects.

Table-4: Prevalence of stunting of the selected adolescent girls

\begin{tabular}{|l|l|l|l|}
\hline Age (year: month) & Height for age $(\mathrm{cm})$ & $\begin{array}{c}\text { Stunted } \\
\text { percentile) } \\
(\%)\end{array}$ \\
\cline { 2 - 4 } & $\begin{array}{l}\text { NCHS standard }\left(^{\text {rd }}\right. \\
\text { percentile) }\end{array}$ & Present study (mean + SD) & $01(3.57)$ \\
\hline $11: 0$ to $11: 11(28)$ & 135.0 & $145.89 \pm 5.89$ & $05(10.42)$ \\
\hline $12: 0$ to $12: 11(48)$ & 140.6 & $147.7 \pm 5.84$ & $28(21.05)$ \\
\hline $13: 0$ to $13 ; 11(133)$ & 144.9 & $148.36 \pm 6.15$ & $47(35.07)$ \\
\hline $14 ; 0$ to $14: 11(134)$ & 147.7 & $151.37 \pm 4.90$ & $49(29.88)$ \\
\hline $15 ; 0$ to $15: 11(164)$ & 149.2 & $152.39 \pm 4.67$ & $42(35.59)$ \\
\hline $16: 0$ to $16: 11(118)$ & 150.0 & $153.00 \pm 6.98$ & $18(25.350$ \\
\hline $17: 0$ to $17: 11(71)$ & 150.4 & $153.33 \pm 4.72$ & $12(24.00)$ \\
\hline $18: 0$ to $18 ; 11(50)$ & 150.8 & $152.60 \pm 6.63$ & \\
\hline
\end{tabular}

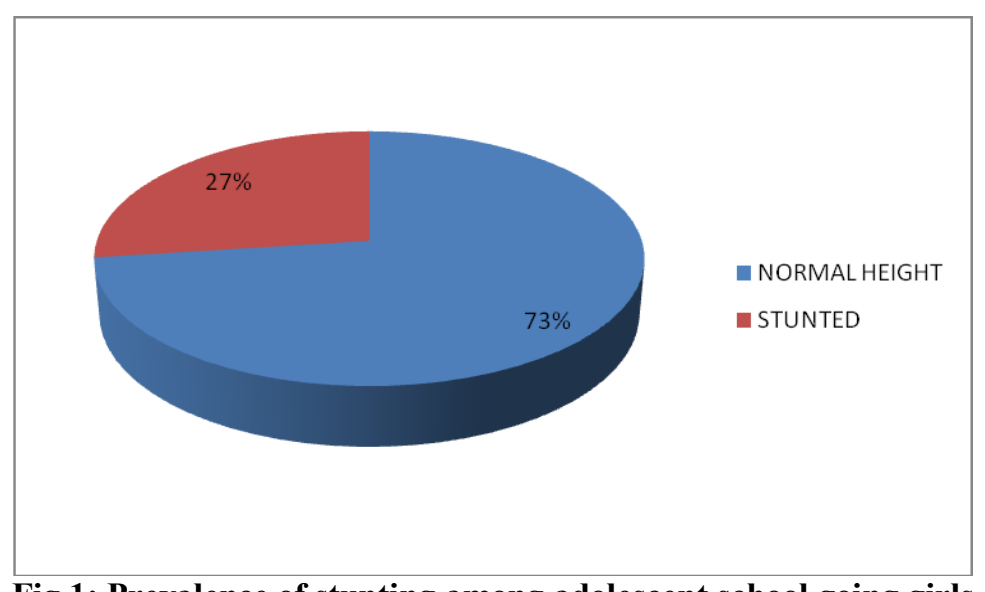

Fig.1: Prevalence of stunting among adolescent school going girls

Health status in respect to BMI was represented in table-5. Nearly $15 \%$ of the subjects, in the present study were found to be thin and $23 \%$ were overweight. 
Table-5: Nutritional status of the selected adolescent girls

\begin{tabular}{|l|l|l|l|}
\hline Age (year) & Thin & Overweight and obese & Normal \\
\hline $11(\mathrm{n}=28)$ & $4(14.290$ & $3(10.71)$ & $21(75.00)$ \\
\hline $12(\mathrm{n}=48)$ & $4(8.33)$ & $9(18.75)$ & $35(72.92)$ \\
\hline $13(\mathrm{n}=133)$ & $7(5.26)$ & $58(43.61)$ & $68(51.13)$ \\
\hline $14(\mathrm{n}=134)$ & $30(22.39)$ & $19(14.18)$ & $85(63.43)$ \\
\hline $15(\mathrm{n}=164)$ & $32(19.51)$ & $31(18.90)$ & $93(56.71)$ \\
\hline $16(\mathrm{n}=118)$ & $20(16.95)$ & $28(23.73)$ & $76(64.41)$ \\
\hline $17(\mathrm{n}=71)$ & $14(19.72)$ & $12(16.90)$ & $47(66.20)$ \\
\hline $18(\mathrm{n}=50)$ & $3(6.00)$ & $11(22.00)$ & $36(72.00)$ \\
\hline
\end{tabular}

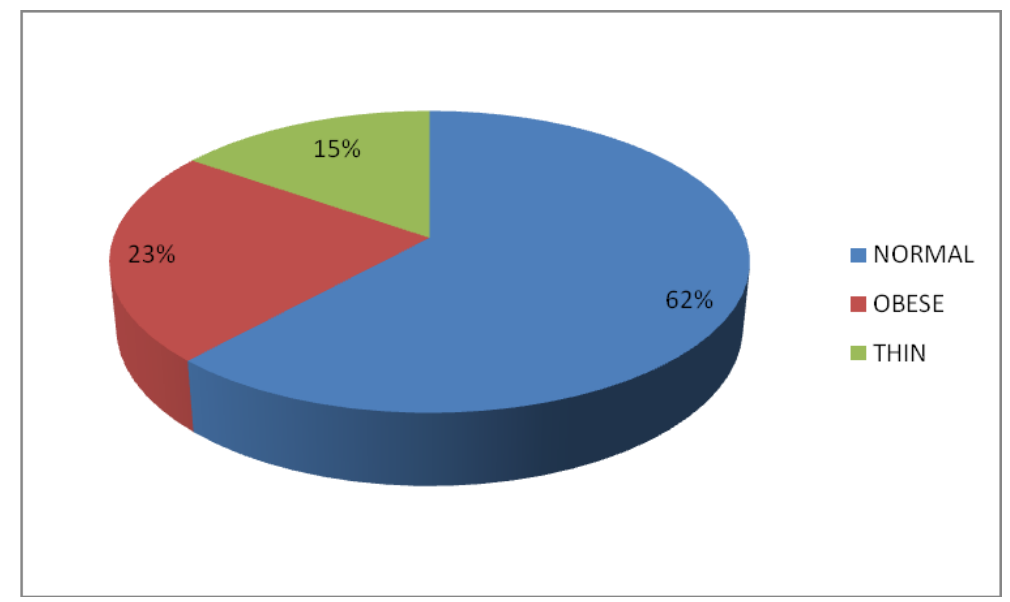

Fig.2: Nutritional status adolescent school girls

To correlate between overweight and life style we studied fast food intake frequency and physical activity status of the selected adolescent girls. Percentage of obesity is more in group of subject those fast food intake frequency was more than other group (table-6).

Table-6: Fast food intake and prevalence of over weight

\begin{tabular}{|l|l|l|l|}
\hline $\begin{array}{l}\text { Frequency of fast food intake ( } \\
\text { day/week) }\end{array}$ & Number of subject & Number (\%) of obese & Significance \\
\hline $0-1$ & 194 & $21(10.82)$ & $\mathrm{Chi}$ square $=40.483$ \\
$\mathrm{~d}=3$ & $\mathrm{p}<0.001$ \\
\hline $4-5$ & 201 & $29(14.42)$ & $45(22.84)$ \\
\hline $6-7$ & 197 & $56(36.36)$ & \\
\hline
\end{tabular}

We found that physical inactivity minimizes chance of overweight. Prevalence of overweight was more in subject those are physically inactive or less active than physically active subjects (table-7).

Table-7: Physical activity and prevalence of over weight

\begin{tabular}{|l|l|l|l|}
\hline Physical activity & Number of subject & Number (\%) of obese & Significance \\
\hline Very mild (<1 hour/day) & 153 & $53(34.64)$ & Chi square \\
\hline Mild (1 hr/day) & 296 & $61(20.61)$ & $=31.326$ \\
\hline Moderate (2-3 hr/day) & 205 & $30(14.63)$ & $\mathrm{df}=3$ \\
\hline Heavy ( $>$ 3hr/day) & 92 & $7(7.61)$ & $\mathrm{p}<0.001$ \\
\hline
\end{tabular}

\section{Discussion}

The aim of this study was to assess the nutritional status of adolescent school going girls having age limit 11-18 years. Height for age below $3^{\text {rd }}$ percentile of NCHS/WHO reference values was considered as stunted and above $3^{\text {rd }}$ percentile as healthy (15). The findings indicate that $27 \%$ of the adolescent girls were found to be stunted (fig.1). This finding is comparable to other micro-level studies carried on adolescent girls in different parts of India $(17,18)$. Stunting has important implications for reproductive health of adolescent girls as it can lead to obstructed labor during child birth due to a small birth canal (19).

$15 \%$ of the study subjects were found to be thin (fig.2). Thinness has implication on reproductive health. It can result in poor pregnancy outcome especially in terms of low birth weight and increased risk of infant mortality (20).

Adolescent obesity is one of the major global health challenges of the $21^{\text {st }}$ century (21). Rapidly changing dietary practices and a sedentary life style have lead to the increasing prevalence of childhood obesity 
(22). Adolescent obesity causes dual problems: firstly obesity is associated with serious medical problems, including high blood pressure, diabetes mellitus, atherosclerotic cardiovascular diseases, coronary heart disease etc. Secondly, overweight and obesity acquired during childhood or adolescence may persist into adulthood and increase the risk of some chronic diseases later in life. $22.92 \%$ of selected adolescent girls were overweight $\left(\mathrm{BMI}>85^{\text {th }}\right.$ percentile) $/$ obese $\left(\mathrm{BMI}>85^{\text {th }}\right.$ percentile).

The new millennium has signaled an important transition for our species with more people being overweight than underweight globally (11). Result of the present study also supports this where thinness was $15.28 \%$ and overweight was $22.92 \%$ (Table-5). In several of the developing nations across the world and even Africa, a continent usually associated with starvation, the prevalence of overweight/obesity is increasing (23). The basic reasons accounting for this change over the last three decades are attributed to a nutrition transitions towards increasing consumption energy dense foods and high calorie liquids as well as an increasing and more stable access to low-priced processed foods $(24,25)$. Our study also supports this observation. We noted significant association between obesity and frequency of fast food intake. These foods are lack of nutrients that body needs to stay healthy, rich in fat and calorie and lacking in protein, vitamins, essential minerals and fibers (26).

Improvements in socioeconomic status of populations are often attributed as another reason (27). Increasing levels of urbanization, mechanization of jobs, transportation and dependence on television for leisure along with parallel declines in physical activity have increased sedentary behaviors of both children and adults (28-30). In our study most of the adolescent girls $(61.8 \%)$ performed very mild to mild physical activity. We also noted significant association between low physical activity and prevalence of overweight/obesity. Obesity/overweight and low physical activity among adolescent and school children was also reported in two different studies, one in China (31) and in Ludhiana (32). Thus rapidly changing diets and lifestyles are fuelling global obesity epidemic (30). The globalization of fast food is also beginning to affect children's eating patterns in many countries undergoing nutrition transition (33).

\section{Conclusion}

The present studies highlight the duel burdens of underweight and overweight in semi urban adolescent girls. Overweight is more urgent problem than underweight. Therefore, to reduce both forms of malnutrition, it is essential to educate and create awareness programme at the community levels. Health education programmes and effective policies are urgently required to promote healthy eating and physical activity. Further studies need to be conducted in order to understand clearly whether the coexistence of underweight and overweight among semi urban adolescent girls is related to the influence of any other reasons.

\section{Acknowledgements}

The authors thankfully acknowledge the cooperation rendered by school authorities, school children and their parents. Their kind cooperation in this investigation is highly cherished from the core of our heart. The authors thank Parthiba Pramanik for his active participation in the preparation of manuscript.

\section{References}

[1]. Parimalavalli R, Sangeetha M. Anthropometric measurements and nutrient intake of adolescent girls. Anthropologist. 2011; 13(2): $111-115$.

[2]. Gopalon C, Sastri BP, Balasubramanian SC. Nutritive value of Indian foods. Hyderabad; National Institute of Nutrition (ICMR); 2001.

[3]. Mukhopadhyay A, Bhadra M, Bose K. Anthropometric assessment of nutritional status of adolescents of Kolkata, West Bengal. J human Ecol. 2005; 18(5): 213-216.

[4]. Caballero B. The global epidemic of obesity: an overview. Epidemiologic review. 2007; 29(1): 1-5.

[5]. Doak CM, Adair LS, Monteiro C, Popkin BM. Overweight and underweight coexist within households in Brazil, china and Russia. J Nutr. 2000; 130(12): 2965-2971.

[6]. Adolescents growth in girls-The Indian perspective. Editorial. Indian Pediatrics. 1990; 27: 149-155.

[7]. Singh N, Mishra CP. Nutritional status of adolescentgirls of a slum community of Varanasi. Indian J Pub Health. 2001; 45(4): 128134.

[8]. Venkaiah K, Damayanti K, Nayak MU, Vijayaraghavan K. Diet and nutritional status of rural adolescents in India. Eur J Clin Nutr. 2002; 56(11): 1119-1125.

[9]. Nutrition for improved development out-comes, $5^{\text {th }}$ report on the World Nutrition Status, United Nations Administrative Committee on Coordination/Standing Committee on nutrition, Geneva, Switzerland, 2004.; page 1-143.

[10]. Smith LC, Ruel MT, Ndiaye A. Why is child malnutrition lower in urban than in rural areas? Evidence from 36 developing countries. World Development. 2005; 33(8): 1285-1305.

[11]. Mendez MA, Monteiro CA, popkin BM. Overweight exceed underweight among women in most developing countries. Am J Clin Nutr. 2005; 81(3): 714-721.

[12]. Srihari G, Eilander A, Muthayya S, Kurpad AV, Seshadri S. nutrition status of affluent Indian school children: what and how much do we know. Indian Pediatr. 2007; 44(3): 204-213.

[13]. Kaushik JS, Narang M, Parakh A. Fast food consumption in children. Indian Pediatrics. 2011; 17: 97-101. 
[14]. Soudarssanane MB, Karthigeyan M, Stephen S, Sahai A. Key predictors of high blood pressure among adolescent: a simple prescription for prevention. Indian J community Med. 2006; 31(3): 164-169.

[15]. World Health Organization. Physical status: the use and interpretation of anthropometry. Report of WHO Expart Committee, technical Series954. Geneva: W World Health Organization, 1995; 270-276.

[16]. Malhotra A, Jain S. Diet quality and nutritional status of rural adolescent girl beneficiaries of ICDS in North India. Asia Pac J Clin Nutr. 2007; 16 (Suppl): 8-16.

[17]. Anand k, Kant S, Kapoor SK. Nutritional status of adolescent school going children in rural North India. Indian Pediatr. 2002; 39 : $449-452$.

[18]. Kapoor G, Aneja S. Nutritional Disorders in adolescent girls. Indian Pediatr. 1992; 29: 969-973

[19]. Konje JC, Ladipo OA. Nutrition and obstructed labor. Am J Clin Nutr. 2000; 72: S291-S297

[20]. Osrin D, Costello AM. Maternal nutrition and fetal growth: practical issue in International health. Semin . Neonatal 2000; 5: 209219

[21]. Story M, Sallis JF, Orleans CT. Adolescent obesity: toward evidence -based policy and environmental solution. J Adolesc Health. 2009; 45(3 suppl): S1-S5.

[22]. Jagmeet M, Neha G, Paarmi V, Princee K. Body fat percentage and its correlation with dietary pattern, physical activity and life style factors in school-going children of Mumbai, India. J Obesity Metab Res. 2014; 1(1): 14-19.

[23]. Sing MS , Neetadevi RK. Nutritional status among the urban Meitei children and adolescents of Manipur, Northeast India. J Anthropology. http;//dx.doi.org/10.1155/2013/983845

[24]. Drewnowski A. Popkin BM. The nutrition transition: new trend in the global diet. Nutr Rev. 1997; $55(2): 31-43$.

[25]. Popkin BM. The world is fat: fads, trends, policies and products that are fattening the human race. Avery, New York, NY, USA. 2009; page 83-101..

[26]. Anderson PM, Butcher KE. Childhood obesity: trends and potential causes. Future Child. Spring 2006; 16: 19-45.

[27]. Sobal J, Stunkard AJ. Socioeconomic status and obesity: a review of the literature. Psychological Bull. 1989; 105(2): 260-275.

[28]. Hill JO, Peters JC. Environmental contribution to the obesity epidemic. Science. 1998; 280: 1371-1374.

[29]. Jeffrey RE, French SA. Epidemic obesity in the United States: are fast food and television viewing contributing? Am J Pub Health. $1998 ; 88 ; 277-280$

[30]. World Health Organization. Diet, nutrition and the prevention of chronic diseases. Report of a joint WHO/FAO Expart Consultation. Technical report no 916, WHO, Geneva, Switzerland, 2003; page-1-160.

[31]. Li M, Dibley MJ, Sibbritt D, Yan H. Factors associated with adolescents' overweight and obesity at community, school and household levels in Xian city, China: results of hierarchical analysis. Eur J Clin Nutr. 2008; 62(5): 635-643.

[32]. Pandher AK, Singha J, Chawla P. Childhood obesity among Punjabi children in relation to physical activity and their blood pro file. J Hum Ecol. 2004; 15(3): 179-182.

[33]. UliJasZek SJ, Lofink H. Obesity in bio cultural perspective. Ann Rev Anthropology. 2006; 35: $337-360$. 